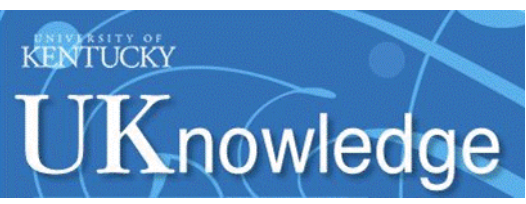

University of Kentucky

UKnowledge

3-16-2017

\title{
Utilizing pHluorin-Tagged Receptors to Monitor Subcellular Localization and Trafficking
}

Ashley M. Fox-Loe

University of Kentucky

Brandon J. Henderson

Marshall University

Christopher I. Richards

University of Kentucky, chris.richards@uky.edu

Follow this and additional works at: https://uknowledge.uky.edu/chemistry_facpub

Part of the Biology Commons, Cell and Developmental Biology Commons, and the Chemistry

Commons

Right click to open a feedback form in a new tab to let us know how this document benefits you.

\section{Repository Citation}

Fox-Loe, Ashley M.; Henderson, Brandon J.; and Richards, Christopher I., "Utilizing pHluorin-Tagged Receptors to Monitor Subcellular Localization and Trafficking" (2017). Chemistry Faculty Publications. 114.

https://uknowledge.uky.edu/chemistry_facpub/114

This Article is brought to you for free and open access by the Chemistry at UKnowledge. It has been accepted for inclusion in Chemistry Faculty Publications by an authorized administrator of UKnowledge. For more information, please contact UKnowledge@lsv.uky.edu. 


\section{Utilizing pHluorin-Tagged Receptors to Monitor Subcellular Localization and Trafficking}

Digital Object Identifier (DOI)

https://doi.org/10.3791/55466

\section{Notes/Citation Information}

Published in Journal of Visualized Experiments, issue 121, e55466, p. 1-7.

Copyright @ 2017 Journal of Visualized Experiments

The copyright holder has granted the permission for posting the article here. 


\title{
Video Article \\ Utilizing pHluorin-tagged Receptors to Monitor Subcellular Localization and Trafficking
}

\author{
Ashley M. Fox-Loe ${ }^{1}$, Brandon J. Henderson ${ }^{2}$, Christopher I. Richards ${ }^{1}$ \\ ${ }^{1}$ Department of Chemistry, University of Kentucky \\ ${ }^{2}$ Department of Biomedical Sciences, Marshall University
}

Correspondence to: Christopher I. Richards at chris.richards@uky.edu

URL: https://www.jove.com/video/55466

DOI: doi: $10.3791 / 55466$

Keywords: Biophysics, Issue 121, Superecliptic pHluorin, receptor, membrane trafficking, subcellular localization, plasma membrane insertion, total internal reflection fluorescence microscopy, membrane protein, upregulation

Date Published: 3/16/2017

Citation: Fox-Loe, A.M., Henderson, B.J., Richards, C.I. Utilizing pHluorin-tagged Receptors to Monitor Subcellular Localization and Trafficking. J. Vis. Exp. (121), e55466, doi:10.3791/55466 (2017).

\section{Abstract}

Understanding membrane protein trafficking, assembly, and expression requires an approach that differentiates between those residing in intracellular organelles and those localized on the plasma membrane. Traditional fluorescence-based measurements lack the capability to distinguish membrane proteins residing in different organelles. Cutting edge methodologies transcend traditional methods by coupling $\mathrm{pH}-$ sensitive fluorophores with total internal reflection fluorescence microscopy (TIRFM). TIRF illumination excites the sample up to approximately $150 \mathrm{~nm}$ from the glass-sample interface, thus decreasing background, increasing the signal to noise ratio, and enhancing resolution. The excitation volume in TIRFM encompasses the plasma membrane and nearby organelles such as the peripheral ER. Superecliptic pHluorin (SEP) is a pH sensitive version of GFP. Genetically encoding SEP into the extracellular domain of a membrane protein of interest positions the fluorophore on the luminal side of the ER and in the extracellular region of the cell. SEP is fluorescent when the pH is greater than 6, but remains in an off state at lower $\mathrm{pH}$ values. Therefore, receptors tagged with SEP fluoresce when residing in the endoplasmic reticulum (ER) or upon insertion in the plasma membrane (PM) but not when confined to a trafficking vesicle or other organelles such as the Golgi. The extracellular $\mathrm{pH}$ can be adjusted to dictate the fluorescence of receptors on the plasma membrane. The difference in fluorescence between TIRF images at neutral and acidic extracellular $\mathrm{pH}$ for the same cell corresponds to a relative number of receptors on the plasma membrane. This allows a simultaneous measurement of intracellular and plasma membrane resident receptors. Single vesicle insertion events can also be measured when the extracellular $\mathrm{pH}$ is neutral, corresponding to a low $\mathrm{pH}$ trafficking vesicle fusing with the plasma membrane and transitioning into a fluorescent state. This versatile technique can be exploited to study localization, expression, and trafficking of membrane proteins.

\section{Video Link}

The video component of this article can be found at https://www.jove.com/video/55466/

\section{Introduction}

Changes in receptor expression, distribution, and assembly have been connected to a wide variety of diseases, including Alzheimer's disease, Parkinson's disease, cystic fibrosis, and drug addiction ${ }^{1,2,3,4,5}$. For example, nicotine and other nicotinic ligands influence the trafficking of nicotinic acetylcholine receptors (nAChRs) leading to changes in trafficking, expression, and upregulation ${ }^{1,2,5,6,7,8,9,10}$. Nicotine increases the total number of assembled nAChRs within a cell, increases trafficking towards the plasma membrane, and alters the assembly of subunits to favor a high sensitivity version of some subtypes. Resolving distinct changes in trafficking, assembly, and expression of receptors in a disease model provides crucial mechanistic details that are essential to define drug targets. An ideal approach would rapidly differentiate between intracellular receptors and those localized on the plasma membrane. This is particularly challenging in cases where a majority of a particular protein resides intracellularly, such as with $\mathrm{nAChRs}$. Since the majority of $\mathrm{nAChRs}$ are localized to the endoplasmic reticulum, traditional measurements lack the spatio-temporal resolution necessary to pinpoint localization and trafficking changes along the secretory pathway. Receptor trafficking and expression studies of nAChRs have primarily been conducted using radioligand binding ${ }^{11}$, biotinylation assays ${ }^{12}$, western blotting ${ }^{13}$, or immunoprecipitation techniques ${ }^{12}$. These depend on the binding specificity of a reporter molecule or fixation of cells and lack the ability to simultaneously distinguish between plasma membrane resident and intracellular receptors. Therefore, studies of ion channel assembly and vesicle dynamics have largely relied on low-throughput electrophysiological techniques ${ }^{14}$.

Superior spatial and temporal resolution is possible with advances in fluorescence microscopy. Genetically encoded reporter molecules, such as green fluorescent protein (GFP) and its variants, eliminate nonspecific binding issues and increase sensitivity ${ }^{15}$. A pH sensitive variant of GFP, known as superecliptic pHluorin (SEP), can be used to exploit inherent $\mathrm{pH}$ differences between compartments within a cell to determine localization $5,7,8,9,16,17,18$. SEP fluoresces when the $\mathrm{pH}$ is higher than 6 , but remains in an off state at lower $\mathrm{pH}$. Therefore, receptors tagged with SEP on their luminal side are detected when present in the endoplasmic reticulum (ER) or upon insertion into the plasma membrane (PM), but not when confined to a trafficking vesicle. Manipulation of the extracellular $\mathrm{pH}$ in contact with receptors on the plasma membrane consequently alters the fluorescence and therefore detection of these receptors. If the same cell is sequentially imaged at both a neutral extracellular $\mathrm{pH}$ and then a $\mathrm{pH}$ lower than 6 , the difference between the images is attributed to receptors located on the plasma membrane. This allows a 
simultaneous measurement of intracellular (peripheral ER) and plasma membrane resident receptors ${ }^{5,7,8,9}$. Single vesicle insertion events can also be resolved when the extracellular $\mathrm{pH}$ is neutral. Once a low $\mathrm{pH}$ trafficking vesicle fuses with the plasma membrane, the luminal side of the vesicle is exposed to the neutral extracellular solution, causing a transition detected as a burst of fluorescence ${ }^{7,18,19,20}$. SEP enables the measurement of receptors localized to the plasma membrane and peripheral endoplasmic reticulum, and provides a means to measure trafficking of receptors between these subcellular regions ${ }^{5,7,18}$.

To achieve higher resolution at the plasma membrane, a receptor with SEP genetically encoded is imaged by total internal reflection florescence microscopy (TIRFM). This method is particularly useful if the majority of receptors are localized to intracellular regions, since TIRFM increases the visibility of the plasma membrane. TIRFM also enables the resolution of trafficking dynamics of single vesicles carrying SEP-labeled receptors upon insertion into the PM. Total internal reflection occurs at the interface of materials with different refractive indices, such as between a cell and a glass cover-slip ${ }^{21,22}$. SEP fluoresces when irradiated with $488 \mathrm{~nm}$ excitation, which is oriented to achieve total internal reflection at the interface of the glass and cell solution. This produces an evanescent wave that penetrates approximately $150 \mathrm{~nm}$ into the sample, only exciting fluorophores within this volume. Only SEP containing receptors in a neutral $\mathrm{pH}$ environment within this range of excitation are detected, corresponding to those residing on the plasma membrane or peripheral endoplasmic reticulum. Since detection is limited to excitation by the evanescent wave, background fluorescence from the intracellular region is reduced and the signal to noise ratio is increased ${ }^{21,22}$. In addition, since radiation does not penetrate the bulk of the cell, photodamage is minimized which allows live cell imaging over the course of time. As a result, TIRFM coupled with genetically encoded SEP provides the high resolution and sensitivity required to measure subcellular localization and trafficking dynamics of membrane receptors along the secretory pathway.

\section{Protocol}

\section{Cell Culture and Transfection}

\section{Maintain mouse neuroblastoma 2a (N2a) cells in growth media}

1. Make $500 \mathrm{ml} \mathrm{N2a}$ growth media from $200 \mathrm{ml}$ Dulbecco's Eagle medium (DMEM) with high glucose, $250 \mathrm{ml}$ reduced serum media, 50 $\mathrm{ml}$ fetal bovine serum (FBS), and $5 \mathrm{ml}$ penicillin/streptomycin (100x).

2. Maintain cells in a $\mathrm{T} 75$ flask at $37^{\circ} \mathrm{C}$ in a $5 \% \mathrm{CO}_{2}$ incubator.

3. Split cells $1: 15$ when necessary, or at approximately $80-90 \%$ confluency. This is typically $2-3$ times a week.

\section{Coat $35 \mathrm{~mm}$ glass bottom dish with poly-D-lysine.}

1. In a laminar flow biosafety cabinet, add $200 \mu \mathrm{l}$ of $0.1 \mu \mathrm{g} / \mathrm{ml}$ poly-D-lysine onto glass bottom region of sterile $35 \mathrm{~mm}$ dish

2. Place dish in a $37^{\circ} \mathrm{C}$ incubator for $1 \mathrm{hr}$.

3. Carefully rinse dish with $\mathrm{ddH}_{2} \mathrm{O} 3-4$ times.

4. Allow dishes to completely dry for more than $1 \mathrm{hr}$.

5. Sterilize dishes using UV light in the biosafety cabinet if necessary.

3. Plate N2a cells for TIRFM imaging.

1. Remove growth media from adherent cells.

2. Detach cells from the flask by incubating with $1 \mathrm{ml} 1 \mathrm{x}$ trypsin (+EDTA) for $5 \mathrm{~min}$ at $37^{\circ} \mathrm{C}$ in a $5 \% \mathrm{CO}_{2}$ incubator.

3. Inactivate trypsin by adding $9 \mathrm{ml}$ growth media. Mix media, trypsin, and detached cells using a pipette.

4. Visually count cells using a hemocytometer and calculate the correct volume to add 90,000 cells to each poly-D-lysine coated glass bottom dish. This density is required for efficient transfection and single cell TIRF imaging.

5. Add $2 \mathrm{ml}$ growth media to each glass-bottom dish containing 90,000 cells.

6. Incubate the dish at $37^{\circ} \mathrm{C}$ in a $5 \% \mathrm{CO}_{2}$ incubator for $16-24 \mathrm{hr}$.

\section{N2a transfection}

1. Obtain a plasmid construct containing an SEP fluorophore incorporated into the extracellular region of the protein of interest. Standard cloning techniques such as PCR amplification ${ }^{5}$ can be used to generate the construct.

NOTE: SEP should be incorporated into the extracellular region of the membrane protein so that it resides within the lumen of the endoplasmic reticulum or trafficking vesicles and is exposed to extracellular solution when on the plasma membrane. SEP is similar in size to GFP and similar cloning strategies can be used.

2. Replace the growth media on plated cells with $1.5 \mathrm{ml}$ reduced serum media (e.g., Opti-MEM), approximately 30 min before the addition of the transfection reagent.

NOTE: To study drug induced changes in receptors, an appropriate concentration of drug can be added at the time of the transfection

3. Add $500 \mathrm{ng}$ of each desired plasmid construct to $250 \mu$ reduced serum media (tube 1 ).

4. Add $2 \mu \mathrm{l}$ of the transfection reagent to a separate tube containing $250 \mu \mathrm{l}$ of reduced serum media. Incubate tube 2 at room temperature for $5 \mathrm{~min}$. The ratio of transfection reagent to plasmid DNA should be optimized to express each protein of interest.

5. Combine tubes 1 and 2 to make a solution containing $500 \mu \mathrm{l}$ of transfection reagent and plasmid mix. Incubate at room temperature for $25 \min$.

6. Add the $500 \mu \mathrm{l}$ transfection mix to pre-plated cells for a total volume of $2 \mathrm{ml}$ per dish.

7. Incubate cells at $37^{\circ} \mathrm{C}$ in a $5 \% \mathrm{CO}_{2}$ incubator for $24 \mathrm{hr}$.

8. After $24 \mathrm{hr}$, remove the transfection mix and rinse the cells with growth media and then add $2 \mathrm{ml}$ of growth media to each dish. NOTE: If a drug was added at the time of transfection, it can be replenished again at this step.

9. Incubate cells at $37^{\circ} \mathrm{C}$ in a $5 \% \mathrm{CO}_{2}$ incubator for $24 \mathrm{hr}$.

10. Image cells $48 \mathrm{hr}$ after transfection. 


\section{Live Cell Imaging by Total Internal Reflection Fluorescence Microscopy (TIRFM)}

\section{Imaging set up}

1. Perform imaging with an inverted fluorescence microscope set-up with a scanning stage as shown in Figure 1. This requires alignment of a $488 \mathrm{~nm}$ DPSS laser source, a stepper motor to adjust $488 \mathrm{~nm}$ beam position, and a high numerical aperture (1.49 NA) $60 \mathrm{X}$ or 100X oil immersion objective.

2. Pass the laser beam through the appropriate excitation filter (bandpass $488 / 10 \mathrm{~nm}$ ). Align the polarized laser beam through a single mode fiber connected to a launcher mounted to a stepper motor. In epifluorescence mode, the excitation beam is centered in the middle of the back aperture of the objective.

3. To attain TIRF, use the stepper motor to translate the focused laser beam across the back aperture of the objective lens until the critical angle is reached and beam is no longer transmitted through the sample and is instead totally reflected off the glass-cell interface.

4. Capture images using an EMCCD $(512 \times 512$ pixels $)$ controlled with imaging software (e.g. Metamorph) with the appropriate emission filter mounted in the emission pathway $(525 / 50 \mathrm{~nm})$.

\section{Prepare the imaging solution}

1. Prepare $200 \mathrm{ml}$ extracellular solution (ECS) by mixing $150 \mathrm{mM} \mathrm{NaCl}, 4 \mathrm{mM} \mathrm{KCl}, 2 \mathrm{mM} \mathrm{MgCl}, 2 \mathrm{mM} \mathrm{CaCl}_{2}, 10 \mathrm{mM} \mathrm{HEPES}$ and $10 \mathrm{mM}$ glucose in $\mathrm{ddH}_{2} \mathrm{O}$. Stock solutions of $\mathrm{NaCl}, \mathrm{KCl}, \mathrm{MgCl}_{2}$, and $\mathrm{CaCl}_{2}$ can be prepared in advance and combined with fresh $\mathrm{HEPES}$ and glucose on the day of imaging.

2. Adjust the $\mathrm{pH}$ of a solution containing $100 \mathrm{ml} \mathrm{ECS} \mathrm{to} \mathrm{pH} 7.4$. Adjust the remaining $100 \mathrm{ml}$ of ECS to a pH of 5.4. Rinse the transfected cells with $2 \mathrm{ml}$ of ECS $(\mathrm{pH} 7.4)$.

3. Add $2 \mathrm{ml}$ of ECS ( $\mathrm{pH} 7.4)$ to the transfected cells before imaging.

3. Live cell imaging in TIRF

1. Turn on the entire system, including $488 \mathrm{~nm}$ laser, camera, translation stage, and imaging program. Focus the epifluorescence beam and adjust the power to approximately $1 \mathrm{~mW}$ at the $60 \mathrm{X}$ objective.

2. Add oil to the objective and place a dish of transfected cells on the translation stage. Secure the dish in place using stage mounts to ensure it does not move with respect to the stage so the cells can be imaged multiple times.

3. In epifluorescence mode, focus the microscope and locate the fluorescent, transfected cells. Cells will remain focused across several focus planes. Locate single, isolated cells to proceed with TIRF.

4. In the imaging program, set the exposure time to $200 \mathrm{msec}$ and optimize the fluorescence intensity by setting the EM gain.

5. Transition the laser beam into TIRF by translating the beam across the objective in a stepwise manner using the stepper motor. As the critical angle approaches, the beam will visibly translate across the edge of the dish until it converges at the point of total internal reflection on the sample plane.

6. Verify that cells are in TIRF mode by adjusting the focus knob. In TIRF, only one plane of cells can be focused (i.e. approximately 150 $\mathrm{nm}$ from glass interface), producing a very defined image with high resolution of the plasma membrane.

4. Imaging SEP to determine subcellular localization

1. Locate healthy, transfected, single cells in the imaging plane.

2. Acquire a focused image of cell at $\mathrm{pH}$ 7.4. SEP labeled receptors on the plasma membrane and endoplasmic reticulum should be visible.

3. Quickly block the laser beam from reaching the sample to prevent photobleaching.

4. Memorize the stage positions corresponding to each cell using microscope imaging software capable of recording multiple xy locations.

5. Repeat steps 2.4.1-2.4.4 for 20-30 cells per dish while using the software to record the position of each cell.

6. After all the cell images at $\mathrm{pH} 7.4$ are collected, manually remove the $\mathrm{pH} 7.4 \mathrm{ECS}$ solution using a pipette. Do not touch the dish as this could move the memorized stage positions.

7. Carefully add $2 \mathrm{ml}$ of $\mathrm{pH} 5.4 \mathrm{ECS}$ to the dish and wait $10 \mathrm{~min}$. During this time, save previously acquired images.

8. Under the identical set of conditions used to collect images at $\mathrm{pH} 7.4$, move the stage to each saved position and acquire an image of the same cell at $\mathrm{pH}$ 5.4. Cells should look less defined since all detected fluorescence is originating from endoplasmic reticulum confined SEP labeled receptors. Save the $\mathrm{pH} 5.4$ cell images.

\section{Imaging single vesicle insertion events in live cells}

1. Replace growth media of transfected cells with $2 \mathrm{ml} \mathrm{pH} 7.4 \mathrm{ECS}$, or with Leibovitz's L-15 media. The pH of Leibovitz's L-15 media is $\mathrm{CO}_{2}$ independent, allowing imaging to take place over a long period of time if necessary.

2. Place the dish of transfected cells on the stage of the microscope. Secure and focus a single cell in TIRF following Step 2.3 above.

3. If equipped, set the autofocus so the focus does not drift over the period of imaging.

4. Record a series of 1,000 frames, continuously capturing images at a frame rate of $200 \mathrm{msec}$. Bursts of fluorescence will be visible during this time, corresponding to low $\mathrm{pH}$ trafficking vesicles fusing with the plasma membrane, exposing the SEP to the extracellular $\mathrm{pH} 7.4$.

5. Locate another single cell and repeat the above step. Reset autofocus if necessary.

\section{Image Analysis and Data Processing}

\section{Analyzing SEP fluorescence to determine subcellular localization}

1. Open the cell images using an image analysis software such as Metamorph or ImageJ (http://imagej.nih.gov/ij/). Subtract the background from both $\mathrm{pH} 5.4$ and $\mathrm{pH} 7.4$ images using the rolling ball setting.

2. Use an intensity based threshold to quantify fluorescence from a single cell. Manually select a region of interest around the cell in the $\mathrm{pH} 7.4$ image. 
3. Measure the cell area, mean intensity, and integrated density using a plugin in ImageJ or using the built in "Measure" function under the Analyze tab.

4. Repeat steps 3.1.1-3.1.3 for the same cell at $\mathrm{pH} 5.4$, carefully adjusting the intensity based threshold and region of interest in the same manner.

5. After the integrated density is obtained for cell images at both $\mathrm{pH} 7.4$ and 5.4 , calculate the plasma membrane integrated density by subtracting the $\mathrm{pH} 5.4$ value from the $\mathrm{pH} 7.4$ value. The difference corresponds to the relative number receptors on the plasma membrane within the TIRF excitation region.

6. As a measure of trafficking, calculate the relative percentage of SEP labeled receptors located on the plasma membrane compared to the remaining receptors visible in the TIRF excitation volume by dividing the plasma membrane integrated density by the total integrated density at $\mathrm{pH} 7.4$, multiplied by 100 .

\section{Analyzing single vesicle insertion events}

1. Open the series of 1,000 tiff images using image analysis software. Subtract the background from all frames using the rolling ball setting.

2. Adjust the color balance of the recording to maximize intense regions corresponding to vesicle insertion events. Manually count the bursts of fluorescence lasting longer than 3 frames (>600 msec).

\section{Representative Results}

SEP incorporation into a receptor allows direct detection of that receptor in a live cell. Coupled with TIRFM, this allows the evaluation of the relative expression levels on the plasma membrane and the distribution of receptors within the subcellular locations in the region of TIRF excitation. Single vesicle trafficking events can also be resolved.

\section{Relative Expression Levels of SEP-labeled Receptors on Plasma Membrane}

SEP fluorescence upon excitation is dictated by the $\mathrm{pH}$ of the surrounding solution. When SEP is fused with plasma membrane resident receptors, the extracellular $\mathrm{pH}$ can be manipulated to turn this fluorescence on or off $\mathrm{f}^{5,7,8,17}$. When the $\mathrm{pH}$ of the extracellular solution is a physiological 7.4, receptors from both the plasma membrane and the endoplasmic reticulum within the region of TIRF excitation fluoresce. The extracellular solution can then be exchanged with an otherwise identical solution of $\mathrm{pH}$ 5.4. This causes the plasma membrane resident SEP to transition into an off state, meaning all observed fluorescence is now from the endoplasmic reticulum. Figure 2 shows an example of cells imaged at both $\mathrm{pH} 7.4(\mathrm{~A})$ and $\mathrm{pH} 5.4(\mathrm{~B})$. The relative number of receptors on the plasma membrane compared to the peripheral endoplasmic reticulum within the region of TIRF excitation is then calculated mathematically by subtracting the integrated density of the fluorescence at $\mathrm{pH} 5.4$ from that at $\mathrm{pH} 7.4$, represented in Figure 2C. This calculated plasma membrane integrated density corresponds to the relative number of SEPlabeled receptors located on the plasma membrane and within the TIRF excitation volume. Since the plasma membrane and nearby peripheral endoplasmic reticulum are being preferentially excited with TIRF, this subcellular distribution comparison is between receptors localized to these regions, and not the entire intracellular region of the cell.

\section{Subcellular Distribution of SEP-labeled Receptors}

Trafficking of receptors can be measured by comparing the ratio between receptors located on the plasma membrane compared to the endoplasmic reticulum. Dividing the plasma membrane integrated density by the total integrated density at $\mathrm{pH} 7.4$, multiplied by 100 , gives a relative percentage of SEP-labeled receptors located on the plasma membrane ${ }^{5,7}$. As a control, brefeldin $A$ can be added to cells to disrupt intracellular protein trafficking. When brefeldin A is present, virtually all of the detected receptors within the region of TIRF excitation will be confined to the endoplasmic reticulum, resulting in a lower \% PM. Additionally, mutated $(\Delta 508-1539 T)$ cystic fibrosis transmembrane regulator $(\Delta 508$-I539T-CFTR) can be used as a positive control. In the presence of commercially available VX-809, $\Delta 508$-I539T-CFTR expression on the cell surface increases 2 to 3 -fold.

\section{Single Vesicle Insertion Events}

SEP does not fluoresce or photobleach in the low pH of a transport vesicle, but regains fluorescence upon exposure to an extracellular $\mathrm{pH}$ of 7.4 at the plasma membrane ${ }^{7,16,18}$. Insertion events are visualized as a burst of fluorescence at the plasma membrane lasting at least 3 frames (600 $\mathrm{msec}$ ), corresponding to full fusion of the transport vesicle into the plasma membrane, as shown in Figure 3. Before an insertion (Figure 3B), no discernable burst is present. An increase in fluorescence intensity is seen as the transport vesicle arrives (Figure 3C), diffusing across the membrane (Figure 3D-3G), until incorporating into the bulk fluorescence of the cell (Figure 3H-3I). 


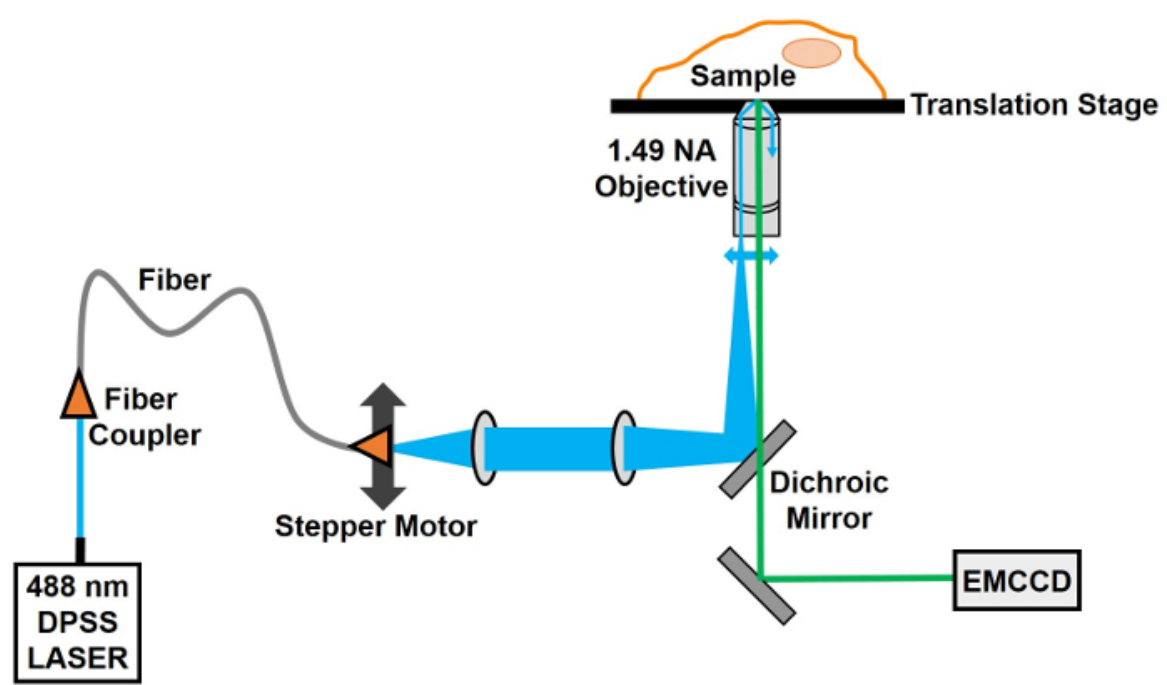

Figure 1: Schematic of TIRF Microscope. This TIRF setup utilizes a $488 \mathrm{~nm}$ DPSS laser for SEP excitation, fiber coupled to a stepper motor to adjust the critical angle of the excitation beam by translating the beam across the back aperture of the objective. Cells are imaged using a $60 \mathrm{X}$, $1.49 \mathrm{NA}$ oil immersion objective. Emission is detected using an electron-multiplying charge coupled device. Please click here to view a larger version of this figure.
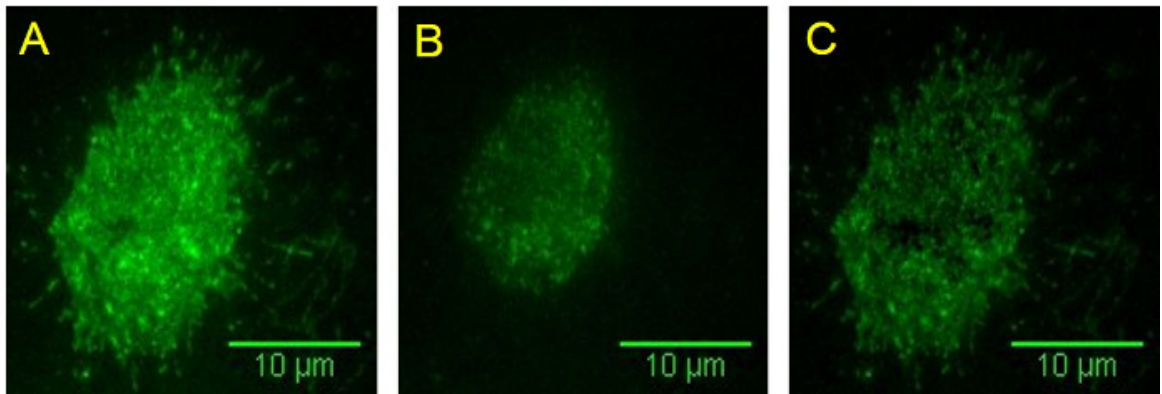

Figure 2: Expression and Trafficking on the Plasma Membrane. An N2a cell expressing $\alpha 3$-sep/ß4-wt nAChRs at pH 7.4 (A) shows receptors located on the plasma membrane and endoplasmic reticulum. At pH 5.4 (B), receptors on the plasma membrane do not fluoresce, so only the endoplasmic reticulum resident receptors are visible. The difference between integrated density at pH 7.4 and pH 5.4 (C) corresponds to receptors localized to the plasma membrane. Please click here to view a larger version of this figure.
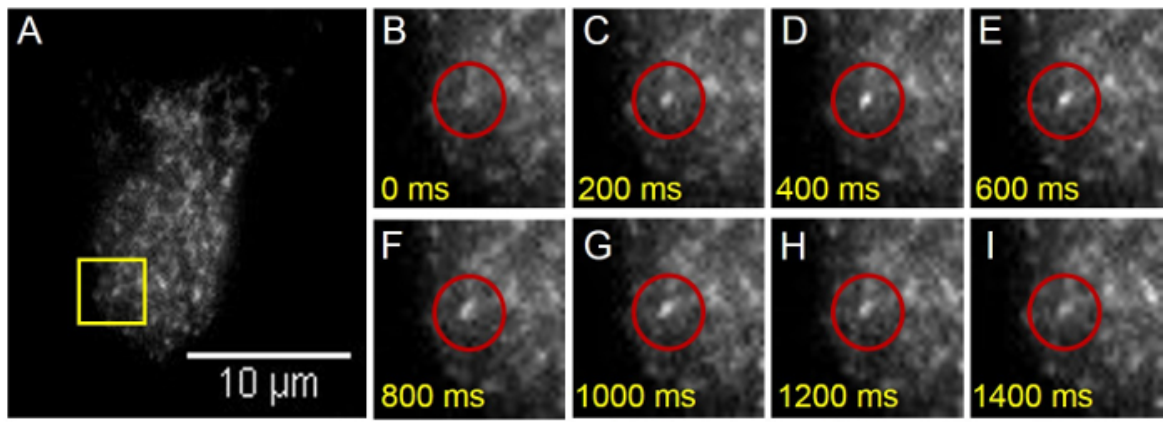

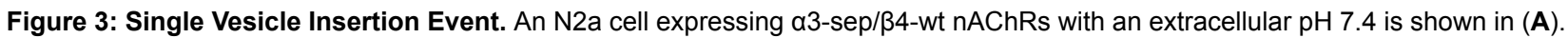
Immediately preceding an insertion (B), no burst of fluorescence is visible. A trafficking vesicle carrying SEP arrives (C), and SEP-labeled receptors diffuse across the plasma membrane (D-G), until indistinguishable from previously inserted receptors $(\mathbf{H}-\mathbf{I})$. Please click here to view a larger version of this figure.

\section{Discussion}

The $\mathrm{pH}$ sensitivity of SEP enables receptors residing on the plasma membrane to be distinguished from intracellular receptors in the endoplasmic reticulum, and it can be used to resolve insertion events of receptor-carrying vesicles ${ }^{5,7,8,9,18,19,20}$. Several techniques including surface biotinylation and ligand binding are widely used to measure protein surface levels. In some cases, western blots can also be used to distinguish between ER and PM resident protein. This SEP-based technique is complementary to traditional measurements, providing a rapid readout of surface expression and the ability to quantify shifts in protein localized on the ER to the PM. Since SEP is genetically encoded in the protein of interest, issues with nonspecific binding are eliminated and sensitivity is increased. SEP undergoes $488 \mathrm{~nm}$ excitation at neutral 
$\mathrm{pH}$, but is not excited under acidic conditions of $\mathrm{pH}<6$. When the extracellular $\mathrm{pH}$ is 7.4 , fluorescence is measured for $\mathrm{nAChRs}$ residing in the endoplasmic reticulum and on the plasma membrane, but not for those in the lower $\mathrm{pH}$ secretory vesicles or Golgi $(\mathrm{pH}<6)^{23}$. During imaging, the ECS of $\mathrm{pH} 7.4$ is exchanged for an otherwise identical solution at $\mathrm{pH} 5.4$. The difference between the integrated density in these images is the plasma membrane integrated density of a cell. Dividing this number by the total integrated density within the region of TIRF excitation, at pH 7.4 , multiplied by 100 , gives the percentage on the plasma membrane $e^{5,7,8,9}$. While these studies used TIRFM, similar assays can be performed using epi-fluorescence. For membrane receptors like nAChR where a majority of receptors reside in the ER, TIRM is ideal because the narrow excitation volume increases the fraction of visible PM resident receptors versus intracellular receptors. This increases the sensitivity of the assay to shifts in receptor distribution between organelles. For proteins with higher expression levels on the PM, epi-fluorescence based SEP studies are sufficient to measure changes in receptor expression. However, single vesicle insertion events which are also measured at $\mathrm{pH} 7.4 \mathrm{require}$ TIRFM. The burst of fluorescence corresponding to the low $\mathrm{pH}$ trafficking vesicle fusing with the higher pH plasma membrane while readily seen in TIRFM is typically not discernable in epi-fluorescence.

\section{Incorporating SEP with TIRF Imaging Conditions}

SEP can be genetically incorporated into the extracellular domain of a membrane protein. Due to the size and location of SEP, it is critical to verify that the modified protein does not significantly differ in trafficking or function from a wild type protein. Assays should be performed using the SEP labeled protein to verify that incorporation of the label did not disrupt activity. For ion channels, electrophysiology and ion permeability measurements are ideal, while for other receptors fluorescent ligand binding and western blotting can be used to verify trafficking. Adherent cells are ideally suited for transfection with commercial transfection reagents and imaging with TIRFM because they attach directly to the glass bottom dish. This attachment is necessary to ensure TIRF excitation by the evanescent wave within about $150 \mathrm{~nm}$ from the glass-sample interface. To achieve high resolution TIRF images, the sample needs to remain flat during imaging ${ }^{21}$. Poly-D-lysine coating is beneficial when imaging N2a cells because it provides an attachment matrix that minimizes cell movements to maintain a flat surface ${ }^{7}$. The plating cell density needs to be optimized to ensure cells are isolated on the glass dish to achieve TIRF. Cell clustering impedes total internal reflection by preventing flat cell adherence in a single optical plane. Since only one plane is focused in TIRF, maintaining proper cell morphology is crucial for imaging. This is particularly important when solutions are being exchanged in the SEP studies. To minimize morphological changes, images at $\mathrm{pH} 7.4$ and $\mathrm{pH}$ 5.4 need to be collected quickly. In addition, the ECS ( $\mathrm{pH} 5.4)$ will eventually permeate intracellular membranes, altering organelle structure and fluorescence of internal SEP-labeled receptors. This is easily avoided by collecting images under each pH condition within a few minutes. Data from multiple dishes in the same imaging session can be combined to increase the number of cells analyzed. When changing solutions, carefully remove the $\mathrm{pH}$ 7.4 ECS solution with a pipette and add pH 5.4 ECS dropwise into the dish. Removing or adding solution too quickly can stress the cells or move the dish with respect to the saved stage positions. A perfusion system to exchange solutions can also be utilized, as long as the solution exchange is complete and occurs quickly. Exact salt concentrations in each solution are required to minimize cell distortions. A stage top incubator can be incorporated to reduce fluctuations in temperature while imaging.

\section{TIRF Imaging}

TIRF imaging reduces background fluorescence by focusing on a single optical plane. This increases the signal to noise ratio by selectively exciting fluorophores within approximately $150 \mathrm{~nm}$ from the glass-sample interface ${ }^{21,22}$. Within this region, resolution is greatly increased, particularly at the plasma membrane. This is necessary if a majority of receptors are located intracellularly. If a high fraction of membrane receptors is located on the plasma membrane, this SEP based approach can be utilized to determine subcellular localization in epifluorescence. However, if a small percentage of total receptors are trafficked to the plasma membrane, as with nAChRs, TIRFM is necessary to quantify $\mathrm{pH}$ dependent changes in fluorescence at the plasma membrane. Also, TIRFM allows the resolution of single vesicle trafficking events and distribution of receptors within the secretory pathway. A basic TIRF setup employs a $488 \mathrm{~nm}$ DPSS laser for SEP excitation, fiber coupled to a stepper motor to adjust the critical angle of the excitation beam. To achieve TIR, the beam is translated laterally across the back aperture of the objective until a critical angle is reached. Cells are imaged using a $60 \mathrm{X}$ or 100X, 1.49 NA oil immersion objective. A numerical aperture higher than the refractive index of the sample (>1.38 for cells) is required to reach the critical angle required for TIRF. A 1.45 NA objective would suffice, but 1.49 NA is more practical when manipulating the angle of excitation. Emission is detected using an electron-multiplying charge coupled device (EMCCD) with an $8 \mathrm{~mm}$ array of $512 \times 512$ pixels. Using a 60X objective, multiple isolated cells can be captured within one field of view.

One of the major drawbacks to fluorescence based studies of protein expression is photobleaching ${ }^{15}$. This excitation induced decomposition of the fluorophore results in an irreversible decrease in fluorescence intensity over time. For this reason, successful imaging relies on a delicate balance between the intensity of the beam of excitation and on-chip gain used within the EMCCD. The excitation intensity needs to be high enough to excite a fluorophore for detection, but not so high as to photobleach the molecule rapidly. Camera gain can be used to multiply the signal for detection, as opposed to increasing excitation intensity, but this also increases background intensity. In addition, care must be taken when choosing the EM gain settings, to avoid saturation of the images. In between measurements, blocking the excitation beam before it reaches the sample minimizes photobleaching. This is required when collecting cell images at an ECS of pH 7.4 to compare to $\mathrm{pH} 5.4$. Photobleaching occurring between the two images is indistinguishable from a lack of fluorescence due to $\mathrm{pH}$ change, so this effect needs to be minimized. Care should be taken to use low laser power and to expose the cell only for the duration necessary to capture the required images. For each experiment, a set of cells can be measured at pH 7 under identical imaging conditions as a control. Using no interval and exposing for a duration matching the exposure time needed for performing the assay provides a control to determine the extent of photobleaching. If photobleaching is greater than $10 \%$ of the original intensity, a correction curve can be used from the observed photobleaching rate by collecting a time trace of fluorescence intensity. For single vesicle insertion events, SEP-labeled receptors in trafficking vesicles are not excited until fusion with the plasma membrane, either because the $\mathrm{pH}$ dictates an off state or they are outside the TIRF region of excitation. Therefore, SEP tagged receptors will not photobleach until insertion, allowing higher excitation power to be used in order to detect single SEP molecules.

In conclusion, this technique can be used with a variety of adherent cell types. SEP can be incorporated into virtually any membrane protein, as long as protein function and trafficking properties are maintained. TIRF enhances the resolution at the plasma membrane. SEP allows the differentiation of tagged proteins located on the plasma membrane from those within the peripheral endoplasmic reticulum. 


\section{Disclosures}

The authors have no conflicts of interest to declare.

\section{Acknowledgements}

This work was supported in part by the National Institute on Drug Abuse T32 DA 016176, National Institute on Drug Abuse DA 038817, and National Institute on Drug Abuse DA 040047.

\section{References}

1. Lester, H. A. et al. Nicotine is a selective pharmacological chaperone of acetylcholine receptor number and stoichiometry. Implications for drug discovery. AAPS J. 11 (1), 167-177 (2009).

2. Henderson, B. J., \& Lester, H. A. Inside-out neuropharmacology of nicotinic drugs. Neuropharmacology. 96 (Pt B), 178-193 (2015).

3. Banerjee, C. et al. Cellular expression of a7 nicotinic acetylcholine receptor protein in the temporal cortex in Alzheimer's and Parkinson's disease-a stereological approach. Neurobiol Dis. 7 (6 Pt B), 666-672. (2000).

4. Ikonomovic M.D., Wecker, L., Abrahamson, E.E., \& et al. Cortical $\alpha 7$ nicotinic acetylcholine receptor and $\beta$-amyloid levels in early alzheimer disease. Arch Neurol. 66 (5), 646-651 (2009).

5. Richards, C. I. et al. Trafficking of $\alpha 4^{*}$ Nicotinic Receptors Revealed by Superecliptic Phluorin. J Biol Chem. 286 (36), $31241-31249$ (2011).

6. Kuryatov, A., Luo, J., Cooper, J., \& Lindstrom, J. Nicotine acts as a pharmacological chaperone to up-regulate human a4b2 acetylcholine receptors. Mol Pharmacol. 68 (6), 1839-1851 (2005).

7. Fox, A. M., Moonschi, F. H., \& Richards, C. I. The nicotine metabolite, cotinine, alters the assembly and trafficking of a subset of nicotinic acetylcholine receptors. J Biol Chem. 290 (40), 24403-24412 (2015).

8. Henderson, B. J. et al. Nicotine exploits a COPI-mediated process for chaperone-mediated up-regulation of its receptors. J Gen Physiol. 143 (1), 51-66 (2014).

9. Henderson, B. J. et al. Menthol Alone Upregulates Midbrain nAChRs, Alters nAChR Subtype Stoichiometry, Alters Dopamine Neuron Firing Frequency, and Prevents Nicotine Reward. J Neurosci. 36 (10), 2957-2974 (2016).

10. Ameen, N., Silvis, M., \& Bradbury, N. Endocytic trafficking of CFTR in health and disease. J. Cyst. Fibros. 6 (1), 1-14 (2007).

11. Pauly, J. R., Marks, M. J., Robinson, S. F., van de Kamp, J. L., \& Collins, A. C. Chronic nicotine and mecamylamine treatment increase brain nicotinic receptor binding without changing a4 or b2 mRNA levels. J Pharmacol Exp Ther. 278 (1), $361-369$ (1996).

12. Govind, A. P., Walsh, H., \& Green, W. N. Nicotine-induced upregulation of native neuronal nicotinic receptors is caused by multiple mechanisms. J Neurosci. 32 (6), 2227-2238 (2012).

13. Mazzo, F. et al. Nicotine-modulated subunit stoichiometry affects stability and trafficking of alpha3beta4 nicotinic receptor. $J$ Neurosci. 33 (30), 12316-12328 (2013).

14. Moroni, M., Zwart, R., Sher, E., Cassels, B. K., \& Bermudez, I. a4ß2 nicotinic receptors with high and low acetylcholine sensitivity: pharmacology, stoichiometry, and sensitivity to long-term exposure to nicotine. Mol Pharmacol. 70 (2), 755-768 (2006).

15. Tsien, R. Y. The green fluorescent protein. Annu Rev Biochem. 67 509-544 (1998).

16. Miesenbock, G., De Angelis, D. A., \& Rothman, J. E. Visualizing secretion and synaptic transmission with pH-sensitive green fluorescent proteins. Nature. 394 (6689), 192-195 (1998).

17. Fox-Loe, A. M., Dwoskin, L. P., \& Richards, C. I. in Neuromethods: Nicotinic Acetylcholine Receptor Technologies. Vol. 117, ed Ming L., Humana Press, (2016).

18. Khiroug, S. S. et al. Dynamic visualization of membrane-inserted fraction of pHluorin-tagged channels using repetitive acidification technique. BMC Neurosci. 10 (141) (2009).

19. Araki, Y., Lin, D. T., \& Huganir, R. L. Plasma membrane insertion of the AMPA receptor GluA2 subunit is regulated by NSF binding and Q/R editing of the ion pore. Proc Natl Acad Sci U S A. 107 (24), 11080-11085 (2010).

20. Yudowski, G. A. et al. Real-time imaging of discrete exocytic events mediating surface delivery of AMPA receptors. J Neurosci. 27 (41), 11112-11121 (2007).

21. Mattheyses, A. L., Simon, S. M., \& Rappoport, J. Z. Imaging with total internal reflection fluorescence microscopy for the cell biologist. J Cell Sci. 123 3621-3628 (2010).

22. Axelrod, D. Total Internal Reflection Fluorescence Microscopy. Methods Cell Biol. 89 169-221 (2008).

23. Paroutis, P., Touret, N., \& Grinstein, S. The pH of the secretory pathway: measurement, determinants, and regulation. Physiol (Bethesda). 19 207-215 (2004). 